\title{
A Educação Ambiental e Atividades Lúdicas: Um incentivo a mudança de hábitos na geração de lixo
}

\author{
Environmental Education and playful-activities: an incentive to change habits in \\ the generation of waste
}

\section{Letícia Mara Ceolin Antqueves ${ }^{1}$, Cláudia Regina Bosa² ${ }^{2}$ Janete Dubiaski-Silva ${ }^{3}$}

\author{
${ }^{1}$ Licenciada em Ciências Biológicas, PUCPR, Curitiba, PR, Brasil \\ ${ }^{2}$ Doutora em Microbiologia, Parasitologia e Patologia, Departamento de Pesquisa e Conservação da Fauna, Prefeitura \\ Municipal de Curitiba, Curitiba, PR, Brasil \\ ${ }^{3}$ Doutora em Zoologia, PUCPR, Curitiba, PR, Brasil
}

\begin{abstract}
Resumo
Uma das metas da Educação Ambiental é sensibilizar a população para que se torne consciente e preocupada com o ambiente e seus problemas. Diante deste fato, com objetivo de chamar a atenção dos participantes das atividades do Acantonamento Ecológico quanto à percepção da quantidade de lixo produzida e descartada por eles, este trabalho propôs uma prática denominada "gincana do lixo" na qual os participantes (crianças de 5a ano da Rede Municipal de Ensino da cidade de Curitiba entre 9 a 12 anos), deveriam descartar os resíduos de forma correta nas lixeiras, posteriormente houve uma discussão sobre os erros e acertos. Os participantes também foram provocados e observados durante a atividade e a partir dos resultados obtidos verificou-se a necessidade de trabalhar o tema não só na escola, mas, em conjunto com a família, pois apesar de todas as campanhas realizadas na mídia a fim de sensibilizar a população sobre a produção de resíduos, a prática das pessoas ainda está longe dos resultados esperados, para tanto deveremos investir em atividades que busquem a mudança de hábitos e podemos atingir esse objetivo por meio de jogos e atividades práticas que façam parte do cotidiano dos estudantes do ensino fundamental.
\end{abstract}

Palavras-chave: Resíduos sólidos, Redução, Reutilização, Ensino Fundamental.

\begin{abstract}
One of the goals of environmental education is to sensitize the population to become an informed and concerned people with the environment and its problems. Given this fact, in order to draw attention of the participants of the activities of the Ecological Cantonment as the perceived amount of waste produced and discarded by them, this paper proposed a practice called "gymkhana trash" where students from (5th year of the Municipal School of Curitiba from 9 to 12 years), should dispose of waste correctly in the dumps, there was a discussion about the rights and wrongs. Participants were also caused and observed during the activity and from the results obtained there was the need to work the theme not only in school but, together with the family, because despite all the campaigns in the media to sensitize the population on the production of waste, the practice of people are still far from the expected results, therefore we must invest in activities that seek to change habits and we can achieve this goal through games and hands-on activities that are part of students' everyday elementary school.
\end{abstract}

Keywords: Solid waste, reduction, recycling, elementary school. 


\section{Introdução}

A tarefa de definir lixo não é fácil, em latim a palavra é derivada do termo lix, que significa "cinza", pois, antigamente os resíduos de cozinha eram formados por cinzas e restos de lenha carbonizada. Também pode derivar de lixare (polir, desbastar) em que o lixo seria então a sujeira, os restos que a lixa arranca dos materiais (BARBOSA, 2000). "Na linguagem técnica, é sinônimo de resíduos sólidos e compreende os materiais descartados pelas atividades humanas" (RODRIGUES e CAVINATTO, 2003).

O lixo faz parte da história dos seres humanos (BIDONE, 1999). Sempre os acompanhando ao longo do tempo, "o fato do ser humano existir traz consigo a existência do lixo na mesma proporção. O primeiro lixo que geramos são as fraldas descartáveis que um dia usamos. Já nascemos gerando descartes" (GRIPPI, 2001).

No começo das civilizações de acordo com Alves (2010), pelas condições simples da população o lixo era mais orgânico e não havia tanta preocupação com o mesmo, pois os materiais utilizados para a fabricação de casas e ferramentas eram retirados da natureza.

As primeiras civilizações eram aglomerados de pequenos grupos de famílias unidas por parentesco [...], e deram origem às aldeias e mais tarde, às cidades. A vida era muito simples, as habitações eram construídas com folhas, cascas de árvores e às vezes pedra empilhada. A subsistência era assegurada pela caça, frutos disponíveis, evoluindo mais tarde (ALVES, $2010 \mathrm{p}$ 11).

Com a revolução industrial, a produção de materiais sofreu um grande salto, chegando ao ponto de gerar produtos com má qualidade para que durem pouco, pois a indústria precisa vender cada vez mais e por meio da mídia incentiva as pessoas a estarem sempre ostentando objetos da moda, desta forma levando ao consumismo (RODRIGUES e CAVINATTO, 2003).

\footnotetext{
Em toda a parte do mundo, a propaganda comercial de jornais, rádio, televisão e da internet incentivam as pessoas a adquirir vários produtos e a substituir os mais antigos pelos mais modernos. Relógios, brinquedos, sapatos ou eletrodomésticos logo ficam "fora de moda" e se transformam em lixo. Logo esses materiais são descartados na natureza, assim como coadores de café, lenços, papel higiênico, copos descartáveis, acumulando pilhas de lixos em aterros sanitários ou em lixões, que já estão saturados (RODRIGUES e CAVINATTO, 2003 p 9).
}

O excesso de trabalho, horas gastas no trânsito, somadas com a correria do dia a dia induzem as pessoas a consumirem comidas prontas, para a economia de tempo. Porém, esses alimentos possuem muitas embalagens produzidas em larga escala compostas por alumínio, papel e plástico, que logo após o consumo serão descartadas (RODRIGUES e CAVINATTO, 2003).

"As modernas redes de lanchonetes ao servir um simples sanduíche acompanhado de bebidas, oferecem caixinhas de papelão ou de isopor, guardanapos, talheres, copos e canudos que serão depositados numa lixeira minutos depois" (RODRIGUES e CAVINATTO, 2003 p $11)$.

Com uma maior geração de lixo, consequentemente também aumenta a variedade deste e os resíduos podem ser classificados em vários tipos conforme a sua origem sendo o lixo urbano, formado por resíduos sólidos em áreas urbanas, incluindo os resíduos domésticos, os efluentes industriais e domiciliares (SEMA, 2009).

Devido aos problemas ambientais gerados pela grande produção de resíduos, principalmente nos ambientes urbanos, várias estratégias vêm sendo desenvolvidas a fim de reduzir e/ou reutilizar estes materiais considerados como sem utilidade, materiais que se tornariam lixo, ou estão no lixo, são 
desviados, sendo coletados, separados e processados para serem utilizados como matéria prima na manufatura de outros bens, que utilizariam matéria prima virgem (GRIPPI, 2001).

"A reciclagem traz muitos benefícios, como a diminuição da quantidade de lixo a ser desnecessariamente aterrado, preservação dos recursos naturais, economia de energia, diminuição da poluição ambiental, geração de empregos diretos e indiretos" (GRIPPI, 2001. p 27).

Para que a reciclagem seja efetiva, devem-se conhecer os diferentes tipos de lixo, a fim de que sejam encaminhados ao seu destino correto. Então o Conselho Nacional do Meio Ambiente CONAMA estabelece o código de cores para os diferentes tipos de resíduos, a fim de facilitar a identificação dos coletores e transportadores, bem como nas campanhas informativas para a coleta seletiva.

O Referido código de cores estabelecido pela Resolução CONAMA 275/01 é:

Azul - Papel e papelão;

Vermelho - Plástico;

Verde - Vidro;

Amarelo - Metal;

Laranja - Resíduos perigosos;

Branco - Resíduos ambulatoriais e de serviços de saúde;

Roxo - Resíduos radiativos;

Marrom - Resíduos orgânicos;

Preto - Madeira;

Cinza - Resíduo geral não reciclável, misturado ou contaminado não passível de separação;

Além da reciclagem deve haver uma mudança de hábitos e a Educação Ambiental é fundamental nesse processo. Segundo a Política Nacional de Educação Ambiental LEI Federal № $9.795(27 / 04 / 1999)$.

Entende-se por Educação Ambiental os processos por meio dos quais o indivíduo e a coletividade constroem valores sociais, conhecimentos, habilidades, atitudes e competências voltadas para a conservação do meio ambiente, bem de uso comum do povo, essencial à sadia qualidade de vida e sua sustentabilidade (BRASIL, LEI Federal № 9.795 (27/04/1999)).

Diante deste fato, deve-se pensar na pedagogia dos 3 R's: reduzir, reutilizar e reciclar, pois são importantes alternativas para a redução da quantidade de resíduos, aumentando o tempo de vida dos aterros sanitários, economizando matéria prima, energia entre outros. Além dos 3 R's podem ser adicionados mais $2 \mathrm{R}^{\prime} \mathrm{s}$ totalizando $5 \mathrm{R}^{\prime} \mathrm{s}$, sendo eles refletir, recusar, reduzir, reutilizar e reciclar. Devemos refletir sobre os nossos hábitos de consumo, recusar produtos que prejudicam o meio ambiente e a saúde, reduzir o consumo desnecessário, reutilizar o máximo antes de descartar e por fim reciclar os materiais (COMINI et al., 2009).

De acordo com Mafaldo e Pinheiro (2011) a Educação Ambiental deve ser prioridade para os governos e sociedade. Ao governo cabem mais investimentos e a sociedade cabe modificar seus hábitos em prol da preservação dos recursos naturais, pois, a única forma de se garantir a manutenção da qualidade de vida no planeta seria com a atuação do ser humano de forma ambiental e ecologicamente correta.

Para proporcionar essa atuação do ser humano de forma ambiental, foi criado o programa de Acantonamento Ecológico, em 1991 que atualmente é desenvolvido pela equipe da Divisão de Educação para a Conservação da Fauna, a qual faz parte da Secretaria do Meio Ambiente (SBZ, 2012).

Atualmente, no projeto do Acantonamento Ecológico a temática do lixo não é trabalhada como uma atividade específica dentro da programação. Muitas escolas pedem atividades sobre o tema e visto que a Educação Ambiental tem como meta "desenvolver uma população que esteja consciente e preocupada com o meio ambiente e com os problemas que lhe são associados" (DIAS, 2003). Ao 
incentivar as crianças a refletirem e mudarem seus hábitos espera-se que este problema ambiental se minimize.

O presente projeto trabalhou com a hipótese de que as atividades realizadas no Acantonamento Ecológico sensibilizam as crianças que participam desse programa e teve como objetivo testar se existe a sensibilização dos alunos do $5^{\circ}$ ano do Ensino Fundamental de Escolas Municipais de Curitiba sobre a temática do lixo - seu destino, separação e reaproveitamento.

\section{Desenvolvimento}

O trabalho foi realizado na Casa de Acantonamento, anexa ao Zoológico Municipal de Curitiba-PR, localizada no Parque Iguaçu. O espaço dispõe de uma casa especialmente projetada para atender 40 crianças, com faixa-etária de 9 a 12 anos. Diversas atividades de Educação Ambiental são realizadas no local, como: trilha interpretativa, horta mandala, pomar, entre outras (BOSA et al., 2007). As atividades de Educação Ambiental são realizadas por técnicos (profissionais formados em: biologia, veterinária, pedagogia e educação física) e estagiários de biologia e técnicos em meio ambiente. Esses transmitem o conhecimento por meio de palestras, atividades recreativas, lúdicas e de sensibilização, durante os finais de semana, com uma escola por final de semana, a qual inicia as atividades no sábado (com pernoite) com finalização das atividades no domingo à tarde (BOSA e SOBOTTA, 2011).

O projeto foi realizado no ano de 2013, durante o mês de março, totalizando três escolas municipais, as quais foram agendadas previamente para a atividade de Acantonamento Ecológico e denominadas como turmas A, B e C.

\section{Descrição das atividades desenvolvidas}

A partir da chegada das crianças ao Acantonamento Ecológico no sábado, estas foram observadas e convidadas a refletir sobre seus hábitos com relação ao lixo através de uma atividade lúdica. Para que o Acantonamento ocorra de maneira organizada e correta, há algumas regras e uma delas é a utilização de canecas de plástico, que as crianças usam durante as refeições. Após o uso das mesmas as crianças devem lavar as suas canecas e guardá-las no lugar correto.

As observações foram registradas em um diário de campo para analise posterior, itens específicos foram analisados - consumo de copos, local de descarte e percepção do lixo.

A intenção do trabalho era provocar as crianças para observar suas reações, ao lado das canecas foram disponibilizados 100 copos descartáveis, para cada dia, afim de que elas pudessem escolher entre o mais prático, que gera mais resíduo ou o mais trabalhoso, mas que pode ser reutilizado ao final do dia os copos foram contados para quantificar o seu consumo.

No decorrer do dia, foram espalhadas algumas embalagens vazias no refeitório, local onde as crianças ficam algum tempo principalmente no horário das refeições, com o objetivo de observar se as mesmas percebiam o lixo e se descartavam o mesmo no local correto. Também foram espalhadas embalagens na horta mandala, um local externo e coberto por um sombrite onde não há lixo.

No final da tarde de sábado, foi realizada a atividade da gincana do lixo (descrita no tópico abaixo), logo após as crianças realizaram outras atividades propostas no Acantonamento no domingo foi aplicado o mesmo procedimento adotado sábado referente aos copos e embalagens.

Para que a atividade pudesse ser realizada, alguns procedimentos legais foram tomados o trabalho foi submetido e aprovado pelo comitê de ética em pesquisa com seres humanos da PUCPR sob o parecer número: 490.447. 


\section{Gincana do lixo}

Nesta atividade as crianças foram divididas em quatro equipes, contendo 10 alunos cada, como é de regra em todos os Acantonamentos. Para cada equipe foram disponibilizadas embalagens de alimentos consumidos pelas crianças no seu dia a dia, como embalagens de salgadinho, bolacha, garrafa pet, guardanapo, latinha de refrigerante e restos de frutas. As crianças não consumiram esses alimentos, pois não faziam parte da alimentação disponibilizada no Acantonamento, com exceção das frutas. Também foram disponibilizadas lixeiras coloridas onde deveriam ser depositados os resíduos, estas não continham identificação com os nomes, somente a coloração referente à normativa do CONAMA 275/01. As equipes tinham cinco minutos para fazer a separação dos resíduos nas lixeiras.

Após o término da atividade os resíduos foram retirados das lixeiras, foi realizada uma tempestade mental (brainstorm) sobre o tema, na qual os participantes foram questionados sobre seus hábitos com o lixo, em locais como escola e casa. Também foi realizada uma discussão sobre os acertos e erros sendo destacada a questão das cores das lixeiras, o tempo de decomposição destes produtos e a produção exagerada do lixo. Por fim esclareceu-se o significado dos 5 R's incentivando-se as crianças a refletir sobre seus hábitos de consumo. A atividade teve aproximadamente uma hora de duração.

A gincana do lixo contou com a presença de uma personagem, que realizou a discussão, um garoto de 17 anos de uma condição social elevada e que veio visitar o Zoológico Municipal de Curitiba, e ao chegar depara-se com muitos resíduos espalhados pelo chão e pede a ajuda das crianças do Acantonamento para realizar o descarte correto. $\mathrm{O}$ mesmo passava a mensagem de que não importa a classe social, idade, etc. Todos podem fazer a sua parte para ajudar o meio ambiente.

\section{Resultados}

As escolas analisadas foram denominadas como A, B e C, todas do município de Curitiba, tendo um total de 108 participantes. A turma A, no decorrer do acantonamento, possuiu dificuldades para assimilar os conteúdos das palestras e atividades, pois o grupo era agitado e ainda estava em fase de transição do $4^{\circ}$ ano para o $5^{\circ}$ ano, tendo visitado o acantonamento no inicio do período letivo. As turmas $\mathrm{B}$ e $\mathrm{C}$ foram bem participativas, pois faziam perguntas.

A Tabela 1 mostra o consumo de copos descartáveis durante o final de semana, foram ofertados 100 copos para o sábado e 100 copos para o domingo totalizando 200 copos, para cada turma, em cada Acantonamento.

Tabela 1 - Consumo de copos descartáveis

\begin{tabular}{ccccc}
\hline CONSUMO DE COPOS & TURMA & TURMA & TURMA \\
DESCARTÁVEIS & A & B & C \\
\hline \multirow{3}{*}{ Sábado } & Café da manhã & 11 & 28 & 52 \\
& Almoço & 0 & 0 & 0 \\
& Lanche da tarde & 89 & 72 & 48 \\
\multirow{3}{*}{ Domingo } & Café da manhã & 0 & 22 & 0 \\
& Almoço & 0 & 0 & 0 \\
& Lanche da tarde & 49 & 51 & 60 \\
\hline & & 149 & 173 & 160 \\
\hline
\end{tabular}

Antes do início das atividades pode-se observar que o consumo de copos descartáveis era maior, principalmente pela turma $C$, que antes do lanche da tarde, já havia utilizado mais que a metade ofertada para aquele dia. Quando os copos acabaram as crianças passaram a utilizar as canecas plásticas lavando-as para que fossem utilizadas novamente. Durante o almoço todas as crianças observadas utilizaram a caneca plástica, voltando a consumir o copo descartável no período 
da tarde para beber água. Domingo houve uma redução no consumo de copos, e na turma B, uma criança alertava as outras para que as mesmas utilizassem a caneca plástica, conforme haviam ouvido na discussão durante a gincana.

Entre uma atividade e outra, as crianças utilizaram os copos descartáveis para beber água, mesmo com as canecas plásticas a disposição.

Tabela 2 - Resíduos espalhados pelo Acantonamento

\begin{tabular}{cccc}
\hline & TURMA A & TURMA B & TURMA C \\
\hline Horta mandala & Não recolhido & Recolhido & Recolhido \\
Refeitório antes da atividade & Não recolhido & Recolhido & Recolhido \\
Refeitório após a atividade & Não recolhido & Recolhido & Recolhido \\
\hline
\end{tabular}

Em relação aos resíduos espalhados pelo Acantonamento, a Turma A, não recolheu o lixo em momento algum, e as crianças pisavam em cima dos resíduos (Figura 1A). Quando questionados se haviam percebido o lixo no refeitório eles responderam que viram o lixo, mas não recolheram e que na horta mandala não haviam visto lixo algum.

A turma B, em um primeiro momento, não recolheu o lixo, porém uma aluna entrou no refeitório e recolheu todos os resíduos sólidos espalhados, descartando-os no local correto. Durante outra atividade, realizada no pomar, uma área anexa ao Acantonamento as crianças deveriam passar por uma trilha e nesta havia algumas embalagens no chão, mas que não faziam parte da atividade. A mesma aluna recolheu o lixo e perguntou onde teria um local para descartá-los. Durante a atividade de horta mandala, sob influência da mesma aluna, as outras crianças ajudaram a recolher os resíduos espalhados no local, após ela ter começado a coletar os resíduos, (Figura 1B e 1C). A partir das informações obtidas na palestra algumas crianças que não haviam coletado o lixo até então passaram a recolher os resíduos Dos 39 participantes da turma C, apenas 3 crianças recolheram o lixo do refeitório e descartaram no local incorreto, porém uma das crianças voltou até a lixeira e corrigiu. Na horta mandala, outras crianças perguntaram se o lixo fazia parte do ambiente, como se fosse algum método para espantar aves e quando dito que não as mesmas recolheram e descartaram os resíduos corretamente. 

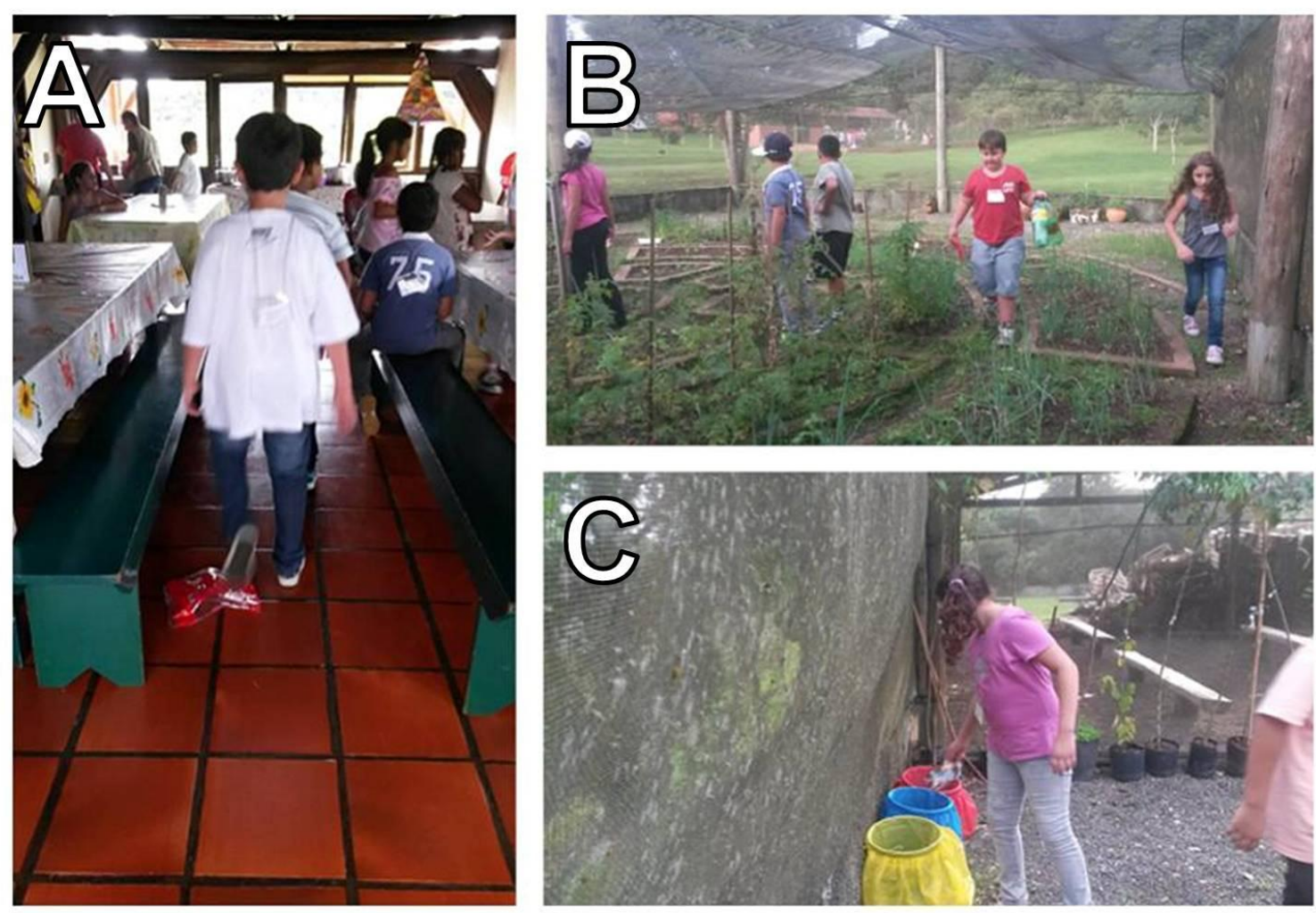

Figura 1. A. Criança passando por cima do lixo. B. Crianças recolhendo os lixos da horta mandala. C. Criança descartando os resíduos.

Após as crianças recolherem o lixo, foi observado se as mesmas descartavam no local apropriado. Também foram observados os resíduos que elas produziam após as refeições e a separação correta durante a gincana.

Tabela 3 - Descarte dos resíduos no local adequado

\begin{tabular}{ccccc}
\hline SEPARAÇÃO & RESÍDUOS & TURMA A & TURMA B & TURMA C \\
\hline \multirow{2}{*}{$\begin{array}{c}\text { Local adequado antes } \\
\text { da atividade }\end{array}$} & Metal & Não se aplica* & Sim & Sim \\
& Plástico & Não & Não & Sim \\
& Papel & Não & Não & Não \\
& Orgânico & Não & Não & Não \\
\hline & Metal & Sim & Sim & Sim \\
Durante a atividade & Plástico & Sim & Sim & Sim \\
& Papel & Sim & Sim & Sim \\
& Orgânico & Sim & Sim & Sim \\
\hline \multirow{3}{*}{ Local adequado após a } & Metal & Não se aplica* & Sim & Sim \\
atividade & Plástico & Não & Sim & Sim \\
& Papel & Não & Não & Não \\
& Orgânico & Não & Não & Não \\
\hline
\end{tabular}

*Materiais que não foram recolhidos 
A turma $\mathrm{A}$, não recolheu os resíduos espalhados, então alguns itens não puderam ser avaliados. Mesmo com a realização da atividade algumas crianças continuaram descartando os resíduos nos locais incorretos em relação ao padrão de cores. Todas as turmas descartaram o guardanapo sujo na lixeira de papel, mesmo sendo enfatizado durante a palestra que não era este o local adequado.

Durante a gincana, quando a personagem pediu o auxílio das crianças para descartar as embalagens no local correto, todas as embalagens foram separadas em seu local adequado.

Também foi observado para está turma que os resíduos eram descartados em qualquer lixeira que apresentasse espaço.

\section{Discussão}

A turma A, por ser um grupo mais disperso e agitado, possuiu dificuldades em absorver o conteúdo, o que ocasionou na falta de sucesso na primeira aplicação da atividade, pois não participaram como o esperado.

Em relação ao consumo de copos descartáveis, uma observação importante a se fazer é que nas escolas da prefeitura, a merenda é servida em pratos e canecas plásticas, presume- se que as crianças estão condicionadas ao uso deles nas refeições, como no almoço, nos lanches não havia pratos, os bolos e salgados eram servidos em guardanapos e as crianças não associaram com o uso das canecas plásticas o que pode explicar o porquê utilizaram os copos descartáveis para estas refeições e na hora do almoço as canecas plásticas.

Embora tenha se discutido com as crianças durante a palestra que o guardanapo é um resíduo que não pode ser reciclado, pois quando em contato com material orgânico, fica contaminado, elas continuaram descartando-os em local incorreto junto aos demais papeis. Em um estudo realizado por Bertoldo e Lima (2012) verificou - se que mais da metade dos entrevistados (alunos da Universidade Tecnológica Federal do Paraná - Câmpus Dois Vizinhos) consideraram que sacos de pão e guardanapos eram resíduos recicláveis, e se confundiram na hora da separação dos mesmos, descartando-os em local incorreto. Observa- se então que este é um comportamento presente no cotidiano das pessoas e que por falta de informação elas acabam descartando estes resíduos erroneamente, o que é prejudicial ao ambiente, pois, contaminam papeis que poderiam ser reciclados, a cada $1000 \mathrm{~kg}$ de papel reciclado 20 árvores são poupadas de corte (SIMONETTO e BORENSTEIN, 2006).

A temática sobre resíduos sólidos já vem sendo trabalhada nas escolas da Rede Municipal de Curitiba. Segundo Muniz (2014) foi criado o programa Sustentabilidade - Mais Tempo de Vida desenvolvido em 2013, pelo Departamento de Ensino Fundamental da Secretaria Municipal da Educação, em parceria com a Secretaria Municipal do Meio Ambiente. Roballo (2013 apud Muniz, 2014) afirma que "o programa visa fortalecer a Educação Ambiental e o desenvolvimento de uma consciência socioambiental, contribuindo para a formação de cidadãos conscientes, comprometidos com a sustentabilidade da vida no planeta". No caso das escolas estudadas parece que esse projeto não está conseguindo a sensibilização desejada, pois em nenhuma delas todo tipo de lixo foi recolhido e colocado adequadamente nas lixeiras antes das atividades serem desenvolvidas enquanto aguardavam o início delas no refeitório. Por outro lado, em duas das escolas os resíduos de metal foram recolhidos adequadamente. Isto pode ser explicado pelo fato de ocorrer uma maior sensibilização para a reciclagem de alumínio devido ao valor do metal reciclado, o Brasil atualmente é considerado o maior reciclador de latas de alumínio no mundo (ABRALATAS, 2015).

A turma $\mathrm{C}$, também teve plásticos recolhidos antes das atividades, esses plásticos eram provenientes de embalagens de alimentos que geralmente são consumidos por crianças, o que pode explicar que elas já possuíam o costume de descarta-los corretamente.

Segundo Kreppner (2000) a família é vista como um sistema social responsável pela transmissão de valores, crenças, ideias e significados que estão presentes nas sociedades. É 
importante que a educação vá além da sala de aula, partindo de uma iniciativa familiar. Dentre os participantes observados percebeu-se que as crianças cujas famílias possuíam hábitos de cuidado com o lixo recolhiam e descartavam os resíduos corretamente, mas era a minoria dentro de um grupo; trabalhar o tema na escola e no Acantonamento Ecológico ainda não foi o suficiente, pois é necessário ampliar o trabalho para que haja a sensibilização das novas gerações fazendo com que no futuro a sociedade se torne, por fim, ecologicamente consciente.

Pode-se dizer que o caminho para um futuro de uma sociedade ecologicamente consciente já esta começando a ser trilhado, pois, com o slogan "Reduza, reutilize, recicle, faça a sua parte" a Prefeitura Municipal de Curitiba lançou uma campanha que tem como foco principal incentivar os cidadãos curitibanos a reduzir a quantidade de lixo gerado na cidade; a campanha conta com o Dr. Sigmundo, um psicanalista que orienta através de conselhos à população, esta transmite de forma divertida informações à população a respeito dos resíduos, como descartá-los corretamente e os convida a uma reflexão sobre a geração de lixo.

\section{Considerações finais}

A educação deve ser prioridade para os governos e sociedade. Ao governo cabem mais investimentos em Educação Ambiental e ao indivíduo entender que ele também faz parte do meio ambiente e adote um modo de vida mais consciente.

Observa-se que diante dos resultados obtidos o objetivo foi alcançado com êxito; verificou-se também uma necessidade de ampliação do trabalho e discussão do tema, pois a sociedade ainda não está sensibilizada sobre os problemas ambientais associados ao lixo da forma como deveria. Também deve se trabalhar mais sobre o descarte de materiais orgânicos, até mesmo a campanha do Dr. Sigmundo não trabalha está questão.

\section{Agradecimentos}

À Equipe da Casa de Acantonamento Ecológico e as escolas participantes sem as quais o presente trabalho teria sido impossível e em especial a veterinária Lucyenne Giselle Popp Brasil Queiroz "Lu popp" pelas valiosas discussões e sugestões no decorrer do trabalho e ao estagiário Vinicius Felipe Oliveira Dias pelo apoio.

\section{Referências}

Abralatas - Associação Brasileira dos Fabricantes de Latas de Alta Reciclabilidade [Internet] (BR) [cited 2015 jul 15] MUNDO: Índices de reciclagem da lata de alumínio para bebidas - 1991 a 2013 (em \%) Available from: http://www.abralatas.org.br/grafico/grafico-8/

Alves, J. D. O luxo da casa do lixo: moradia e sustentabilidade. Goiânia: Ed da PUC Goiás; 2010.

Barbosa S. - 2000 - Classificação [Internet]. Lixo consciência sócio ambiental Jun 00 [cited 2013 Jul 08] Available from:

http://www.lixo.com.br/index.php?option=com_content\&task=view\&id=143\&Itemid=

Bertoldo G, Lima DM. Levantamento sobre a separação de lixo na UTFPR - Câmpus Dois Vizinhos. In: II Seminário de Extensão e Inovação SEI'2012 [Internet]; 2012 set 17; Paraná, Brasil. 2012 [cited 2015 jul 03]. available at: http://www.sei.utfpr.edu.br/images/arquivos_2012/LEVANTAMENTO\%20SOBRE\%20A\%20SEPA 
RA\%C3\%87\%C3\%83O\%20DE\%20LIXO\%20NA\%20UTFPR\%20\%E2\%80\%93\%20C\%C3\%82MPUS\% 20DOIS\%20VIZINHOS.pdf

Bidone FRA. Programa de pesquisa em saneamento básico. Metodologias e técnicas de minimização, reciclagem e reutilização de resíduos sólidos urbanos. Rio de Janeiro: ABES. 1999

Bosa CR. Franco JRS. Silva MET. Moraes SRM. Educação Ambiental: caminhos para mudar. Curitiba. Revista Acadêmica, 2007 v.5, n. 4, p. 425-435.

Bosa CR. Sobota AR. Educação Ambiental: no acantonamento ecológico, Curitiba, Paraná. Revista Monografias Ambientais [Internet]. 2011 [cited 2013 ago 13] v. 2, n. 2 (2011) Author's manuscript available at: http://cascavel.ufsm.br/revistas/ojs-2.2.2/index.php/remoa/article/view/2651

Brasil. Lei 9.795, de 27 de abril de 1999. Publicada no Diário Oficial da União em 28 de abril de 1999

Comini GS. Honda IM. Fernandes JC. Maciel MSD. Digressão sobre a inserção da variável sustentabilidade socioambiental no planejamento estratégico das organizações. CEFET/RJ-CSF. Revista Tenda, 2007, n. 3.

Conselho Nacional do Meio Ambiente - CONAMA. Resolução CONAMA nº 275. Estabelece o código de cores para os diferentes tipos de resíduos. (Brasil): CONAMA 2001.

Dias GF. Educação Ambiental: Princípios e Práticas. São Paulo: Gaia. 2003.

Grippi S. Lixo: reciclagem e sua história: um guia para as prefeituras brasileiras. Rio de Janeiro: Interciência. 2001.

Kreppner K. [The child and the family: Interdependence in developmental pathways]. Psicologia: Teoria e Pesquisa, 2000, 16(1), 11-22.

Mafaldo MFG. Pinheiro KD. Ensinando técnicas de reciclagem, reutilização e redução dos resíduos sólidos urbanos para alunos do $4^{\mathrm{o}}$ ano do ensino fundamental da E E E F , Eduardo Vargas em Alegrete/RS. Revista Monografias Ambientais [Internet]. 2011 [cited 2013 jul 08] v. 3, n. 3 (2011) available at: http://cascavel.ufsm.br/revistas/ojs-2.2.2/index.php/remoa/article/view/3044/1824

Muniz C. - 2014 - Comunidade escolar será envolvida em programa de educação para sustentabilidade [internet]. Secretaria Municipal da Educação de Curitiba; [cited 2015 mar 07] Available from http://www.cidadedoconhecimento.org.br/cidadedoconhecimento/index.php?subcan=7\&cod_not= 41046

Rodrigues FL. Cavinatto MV. Lixo: De onde vem? Para onde vai? (2를 Ed) São Paulo: moderna 2003.

Secretaria de Estado do Meio Ambiente e Recursos hídricos (SEMA): Desperdício zero: comece não desperdiçando esta ideia. Paraná (Brasil): Governo do Estado do Paraná, 2009.

Simonetto EO, Borenstein D. Gestão operacional da coleta seletiva de resíduos sólidos urbanos abordagem utilizando um sistema de apoio à decisão. Gest. Prod.[Internet]. 2006 [cited 2015 jul 03]; vol.13, n.3 Available from: http://www.scielo.br/scielo.php?script=sci_arttext\&pid=S0104530X2006000300008\&lng=en\&nrm=iso

Sociedade Brasileira de Zoologia (SBZ). Departamento de Zoologia, UFPR Curitiba, PR. 2012 Boletim informativo Número 103 